\title{
Glucose Release as a Response to Glucagon in Rat Hepatocyte Culture: Involvement of NO Signaling
}

\author{
H. FARGHALI ${ }^{1}$, J. HODIS ${ }^{1}$, N. KUTINOVÁ-CANOVÁ ${ }^{1}$, P. POTMĚŠIL $^{2}$, \\ E. KMONÍČKOVÁ ${ }^{2}$, Z. ZÍDEK ${ }^{2}$
}

${ }^{1}$ Institute of Pharmacology, First Faculty of Medicine, Charles University, Prague, ${ }^{2}$ Institute of Experimental Medicine, Academy of Sciences of the Czech Republic, Prague, Czech Republic

Received March 1, 2007

Accepted May 15, 2007

On-line July 26, 2007

\begin{abstract}
Summary
Glucagon and $\alpha$-adrenergic-induced glycogenolysis is realized via the agonist/adenylyl cyclase/cAMP/protein kinase signaling pathway or via the activation of phosphorylase kinase by the mobilized calcium that supports the inhibition of glycogen synthase, respectively. The role of nitric oxide (NO) in this process has not been extensively studied. The present work was directed to the question whether NO is produced during glucagon-induced glycogenolysis in rat hepatocyte in a similar way like $\alpha$-adrenoceptor stimulation. Glycogen-rich hepatocyte cultures were used. NO production $\left(\mathrm{NO}_{2}^{-}\right)$was assessed under the influence of glucagon, dibutyryl cyclic AMP (db-cAMP), forskolin, the nitric oxide synthase (NOS) inhibitors $N^{\omega}$-nitro-Larginine methyl ester (L-NAME) and aminoguanidine, and the NO donor S-nitroso-N-acetyl penicillamine (SNAP). Inducible NOS (iNOS) mRNA was examined by reverse transcription-polymerase chain reaction. Glycogenolysis was followed up by estimation of medium glucose levels. The amount of glucose and $\mathrm{NO}_{2}^{-}$released by glycogen-rich hepatocytes was increased as a result of glucagon, db-CAMP, forskolin and SNAP treatments. iNOS gene expression was upregulated by glucagon. Glycogenolysis that occurs through glucagon receptor stimulation involves NO production downstream of transduction pathways through an isoform of NO synthase. The present and previous studies document possible involvement of NO signaling in glycogenolytic response to glucagon and adrenergic agonists in hepatocytes.
\end{abstract}

\section{Key words}

Nitric oxide $\bullet$ Glucagon $\bullet$ Glycogenolysis $\bullet$ Hepatocytes

\section{Corresponding author}

H. Farghali, Institute of Pharmacology, First Faculty of Medicine, Charles University, Albertov 4, 12800 Prague 2, Czech Republic. Fax: +420 224968106. E-mail: hfarg@lf1.cuni.cz

\section{Introduction}

It is established that the liver plays a central role in the control of glucose production and that disturbances, which occur in some metabolic diseases, could indicate the presence of alterations in glycogen deposition of various causes with either increase or decrease in liver glycogen. The molecular mechanisms of increased glucose production to identify potential therapeutic targets were reviewed (Proietto and Andrikopoulos 2004, Klover and Mooney 2004) and it has been recognized that hepatocytes are critical for glucose homeostasis. The signaling pathways that participate in hormone-induced glycogen degradation are documented (Decker 1990, Huber and Keppler 1990, Borgs et al. 1996).

Glucagon raises cyclic AMP (cAMP) levels that activate protein kinase A (PKA) and this in turn leads to the activation of phosphorylase and glycogen breakdown. At the same time, PKA phosphorylates and helps to inactivate glycogen synthase. Moreover, epinephrine through its $\alpha_{1}$-adrenergic receptors regulates hepatic glycogenolysis in some animal species. Altogether, glucagon and epinephrine on the one hand, and insulin on the other, determine the status of glycogen store. The regulation of glycogenolysis in hepatocytes by both hormones appears to be equally important under physiological and pathological conditions (Van Ermen and Fraeyman 1994, Moriyama et al. 1997, Shiroyama et al. 1998, Fabbri et al. 1999, Vardanega-Peicher et al. 2000, Manzl et al. 2002, Kalamidas et al. 2002).

Although the pathways that modulate glycogen level in the liver have been fairly well elucidated, the role 
of nitric oxide (NO) in this process is not extensively studied. In our previous work, we found that glycogenolysis in rat hepatocytes that occurs through $\alpha$ adrenergic stimulation involve NO production (Hodis et al. 2007). Indeed, NO exerts functional regulatory effects in all organs, tissues and cells, which were examined including the liver (Muriel 2000, Moreau 2002, Chang et al. 2004, Harbrecht et al. 2004, Voleti and Agrawal 2006). It was reported that NO affects glycogen and glucose homeostasis (Horton et al. 1994a, Horton et al. 1994b, Stadler et al. 1995, Borgs et al. 1996, Sugita et al. 2002). The data available suggest that glucagon may participate in the in vivo regulation of hepatic inducible nitric oxide synthase (iNOS) expression after proinflammatory stimuli. Nevertheless, it is not yet clear to which extent NO is involved in the modulation of glycogenolytic pathways. The present work was, therefore, directed to extend our previous observation by the study that shed more light on whether NO is produced during glucagon-induced glycogenolysis in rat hepatocyte cultures in a similar way like adrenergic stimulation (Hodis et al. 2007). The glycogen-rich rat hepatocytes in culture were used for glycogenolysis studies under glucagon, dibutyryl cyclic AMP (db-cAMP), forskolin, and the NO donor S-nitroso$\mathrm{N}$-acetyl penicillamine (SNAP). NO production was assessed under various treatments.

\section{Materials and Methods}

\section{Chemicals}

Glucagon was obtained in ampoules (Glucagen $1 \mathrm{mg}$ HypoKit inj. sic.) from Novo Nordisk, Denmark. Sulfanilic acid, N-(1-naphtyl)ethylendiamine dihydrochloride, dibutyryl cyclic AMP sodium-potassium salt (db-cAMP), $\quad \mathrm{N}^{\omega}$-nitro-L-arginine methyl ester (L-NAME), aminoguanidine, S-nitroso-N-acetyl penicillamine (SNAP), forskolin ( $7 \beta$-acetoxy- $1 \alpha, 6 \beta, 9 \alpha-$ trihydroxy-8,13-epoxy-labd-14-en-11-one), dimethyl sulfoxide (DMSO), HEPES, Dulbecco's phosphate buffered saline, William's medium E, gentamycin, L-glutamine and fetal bovine serum (FBS) and bovine serum albumin fraction $\mathrm{V}$ (BSA), were obtained from Sigma-Aldrich (Prague, Czech Republic). Collagenase and glucose assay kit were obtained from Sevapharma and Vian Diagnostika (Prague, Czech Republic), respectively. A commercial kit for nitrite/nitrate colorimetric detection was obtained from Roche Diagnostic (Prague). Other chemicals were obtained from standard sources.
Animals

Male rats of Wistar strain (Velaz-Lysolaje, 200$250 \mathrm{~g}$ body weight) received humane care and the study procedures were carried out in accordance with the Animal Care Guidelines of the First Faculty of Medicine.

Isolation and preparation of glycogen-rich hepatocyte culture

Hepatocytes were isolated from anesthetized rats by a standard two-phase collagenase perfusion method as previously reported (Farghali et al. 1994). After isolation, cell viability was at least $90 \%$ as assessed by trypan blue. The preparation of glycogen-rich hepatocytes was performed according to Shiroyama et al. (1998) with minor modification (Hodis et al. 2007). Hepatocytes from untreated animals were plated into collagen-coated cell culture dishes and maintained at $37^{\circ} \mathrm{C}, 95 \%$ air, and $5 \%$ $\mathrm{CO}_{2}$ in William's medium $\mathrm{E}$, supplemented with gentamycin, L-glutamine, $10 \mathrm{mM}$ HEPES, $6 \% \mathrm{FBS}$, 2x10-

${ }^{7} \mathrm{M}$ insulin and $20 \mathrm{mM}$ glucose overnight. The produced glycogen-rich cells were used to determine glycogenolytic glucose release. High glycogen content of hepatocytes was confirmed biochemically and histochemically (Shiroyama et al. 1998). This model proved to be convenient for the study of glycogenolysis by glucose release since there are no substrates as lactate, amino acids or other types of sugar necessary for gluconeogenesis.

Drug treatments and measurement of glycogenolytic glucose release

The medium of the glycogen-rich hepatocytes was changed to glucose-free Dulbecco's phosphate buffered saline just before the relevant treatment. Glucagon $(0.5-10 \mu \mathrm{g} / \mathrm{ml})$ was added to the glucose-free Dulbecco's phosphate buffered saline medium in culture. Cultured hepatocytes were treated with forskolin $(50 \mu \mathrm{M})$, db-cAMP $(1 \mathrm{mM})$ or SNAP $(25$ and $250 \mu \mathrm{M})$. DMSO at final concentration of less than $1 \%(\mathrm{v} / \mathrm{v})$ used as the solvent for some compounds (e.g. forskolin) was found to be without any effect on the measured parameters. The time course of glucose release was followed till $60 \mathrm{~min}$ of incubation. The estimation of medium glucose levels was done spectrophotometricaly according to the enzymatic glucose assay kit instructions from Vian Diagnostika (Prague, Czech Republic).

\section{Determination of nitric oxide production}

NO production from the cells into the medium was measured in appropriate time intervals as indicated in 
the Results. NO production was determined by measuring the levels of its oxidation products $\mathrm{NO}_{2}{ }^{-}$and $\mathrm{NO}_{3}{ }^{-}$in the culture medium. This was detected colorimetrically $(540 \mathrm{~nm})$ by Griess reagent and/or by nitrite/nitrate colorimetric method from Roche Diagnostic. The nitrite levels were extrapolated from $\mathrm{NaNO}_{2}$ calibration curve.

Reverse transcriptase-polymerase chain reaction for iNOS expression

The 24-h cultured hepatocytes were used for reverse transcriptase-polymerase chain reaction (RTPCR) without glucagon or under glucagon or LNAME + glucagon treatment. RNA from hepatocytes was isolated by the standard procedure by Quiagen $\mathbb{}$ RNeasy mini kit as described earlier for iNOS (Farghali et al. 2002). Total RNA content was finally measured by spectrophotometry-Eppendorf ${ }^{\circledR}$ BioPhotometer, RNA purity was counted from absorption rate of $260 / 280 \mathrm{~nm}$ respectively. The total RNA was amplified and reverse transcribed into cDNA via RT-PCR. $2.3 \mu \mathrm{l}$ of cDNA formed was treated with PCR reaction mix after following protocol: $\mathrm{Mix}(47.7 \mu \mathrm{l})=\mathrm{H}_{2} \mathrm{O} 33.6 \mu \mathrm{l}+$ red buffer $5.0 \mu \mathrm{l}+$ black $\mathrm{MgCl}_{2} 4.0 \mu \mathrm{l}+$ primer F $0.3 \mu \mathrm{l}+$ primer R $0.3 \mu \mathrm{l}+$ blue NTP $1.0 \mu \mathrm{l}+$ yellow enhancer 1.0 $\mu 1+$ Taq ${ }^{\circledR}$ polymerase $2.5 \mu$ l. Cycler's conditions being: $2^{\prime} 94^{\circ} / / 25 \mathrm{x}\left(20^{\prime \prime} 94^{\circ} / 10^{\prime \prime} 59^{\circ} 1^{\prime} 72^{\circ}\right) / / 10^{\prime} 72^{\circ}$. The primers were constructed as described before (Farghali et al. 2002) 5'-GGC AGA CTG GAT TTG GCT GGT C-3'; R 5'- AGG TGT TCC CCA GGT AGG TAG C-3', comprising exon-intron DNA boundaries eliminating external contaminating DNA to be involved into PCR reaction. The relative level of iNOS mRNA expression was determined after normalization to the $\beta$-actin signal to account for variability in the amount of RNA that had been extracted from cells.

Amplified samples were run on agarose gels and stained with ethidium bromide. Images were captured using a monochrome camera and signal density measured by Kodak 1D Image Analysis Software Version 3.0 and compared to control sample.

\section{Statistical analysis}

In most of the experiments, the protein content of hepatocytes was estimated and was found to be variable per culture plate. Therefore, control culture plate was done for every single experiment. The experiments were performed at a minimum 6-8 times in triplicates (means of 18-24 values \pm S.E.M.) with blind samples as the media background. The statistical significance of difference of mean scores was determined using the unpaired Student's t-test or ANOVA where appropriate. $\mathrm{P} \leq 0.05$ values were considered statistically significant.

\section{Results}

Figure 1 demonstrates that the amount of glucose and nitrite released by glycogen-rich hepatocytes was significantly increased as a function of incubation time by glucagon $(1 \mu \mathrm{g} / \mathrm{ml})$ treatment. These data show that at sampling times 30 and $60 \mathrm{~min}$, both glucose and nitrite levels were higher under glucagon treatment as compared to control treatment. The effects were not evident at time $120 \mathrm{~min}$ (data are not shown). Sampling times of 30 and $60 \mathrm{~min}$ were, therefore, chosen for the subsequent experiments. In hepatocyte culture, treatment with glucagon increased iNOS gene expression (measured by RT-PCR) by about twofold (Fig. 2). This figure shows a photograph of an agarose gel of iNOS mRNA levels, where iNOS mRNA was detected in noninduced control hepatocytes. Following the treatment with glucagon, there was an intense PCR product of iNOS that was observed after $60 \mathrm{~min}$ exposure of hepatocytes in culture. It is clear that L-NAME did not significantly affect the level of iNOS mRNA which was expected because L-NAME is an inhibitor of NOS per se (i.e. post-translation effect).

Table 1 shows the relative effect of five different treatments (30 and $60 \mathrm{~min}$ incubation) on nitrite production and glucose release in hepatocyte culture. Both aminoguanidine and L-NAME at high concentrations were able to decrease significantly $\mathrm{NO}$ production (measured as nitrite) and glycogenolysis (measured as glucose) induced by glucagon. This effect was measurable and significant in most cases at 30 and 60 min with aminoguanidine being more potent. Moreover, Table 1 demonstrates that both db-cAMP and the specific activator of adenylyl cyclase, forskolin, significantly increased both glucose release and nitrite levels.

The effects of exogenously delivered NO (SNAP addition) on glucose release and nitrite levels is demonstrated in Figure 3. As expected, SNAP at 25 and $250 \mu \mathrm{M}$ concentrations in the culture medium produced highly significant concentration-dependent increase in total nitrite levels as compared to control treatment (Fig. 3B). In addition, SNAP significantly increased basal glucose production $30 \mathrm{~min}$ after incubation when compared to control values (Fig. 3A). 

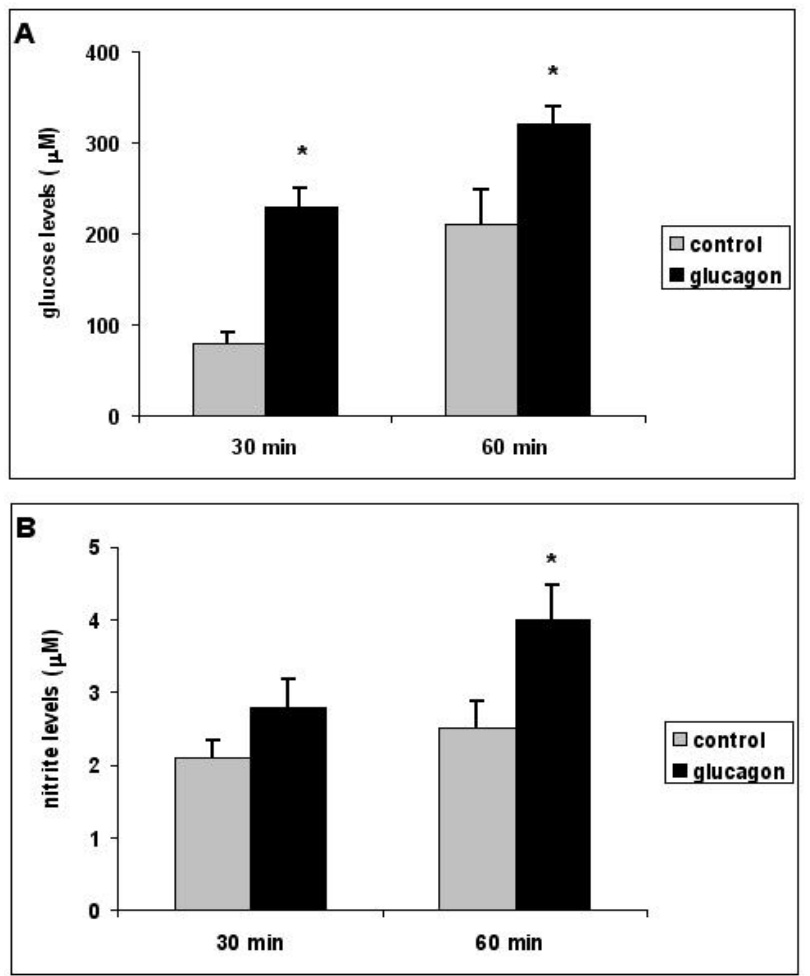

Fig. 1. Glucose (A) and nitrites (B) released to culture medium by glycogen-rich hepatocytes under control conditions and glucagon $(1 \mu \mathrm{g} / \mathrm{ml})$ treatment after 30 and $60 \mathrm{~min}$. Values are expressed as means \pm S.E.M. * Significantly different from the respective control group $(P \leq 0.05)$.

\section{Discussion}

The role of NO in a number of liver functions is being investigated intensively. It was suggested that nitric oxide synthases are players in the pathophysiology of some hepatic diseases (Moreau 2002). In several other reports, it was found that NO affects glycogen and glucose homeostasis (Horton et al. 1994a,b, Stadler et al. 1995, Borgs et al. 1996, Sugita et al. 2002). However, it is still not clear how NO is involved in the modulation of glycogenolytic pathways under physiological conditions. Moreover, there are data which indicate that glucagon may participate in the in vivo regulation of hepatic iNOS expression after proinflammatory stimuli (Harbrecht et al. 2004). The current investigation was motivated by our previous finding on the involvement of NO release in the activation of hepatocyte glycogenolysis after $\alpha$-adrenoceptor stimulation (Hodis et al. 2007). The importance of the present study stems from the fact that liver has a central role in the control of glucose production and that the hepatocytes are the main players. Therefore, research is directed towards finding out

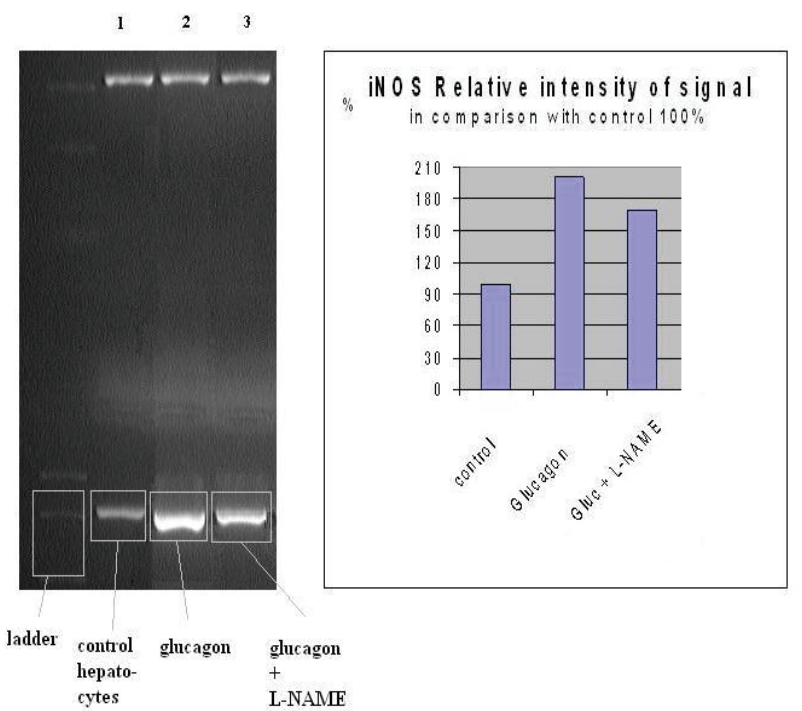

Fig. 2. A representative photograph of an agarose gel of RT-PCR demonstrating iNOS mRNA levels, where columns depict iNOS mRNA ladder with $386 \mathrm{bp}$ and cultured hepatocytes under: 1) no treatment (control), 2) $1 \mu \mathrm{g} / \mathrm{ml}$ glucagon, 3) $1 \mu \mathrm{g} / \mathrm{ml}$ glucagon + $10 \mathrm{mM}$ L-NAME treatment. The graph illustrates the quantified signal density of iNOS PCR products of treated hepatocytes compared to control sample. Results were recorded after $60 \mathrm{~min}$ incubation.

pharmacological means that modulates hepatocyte signaling pathways with consequent alterations in glycogenolysis or gluconeogenesis.

The present data demonstrate that glucagonstimulated glycogenolysis in hepatocytes is accompanied by an increase in NO release. The present findings together with our previous ones (Hodis et al. 2007) demonstrate that NO is released, probably, as a common denominator signal during glycogenolysis as revealed for both $\alpha$-adrenergic- and glucagon-agonistic effects.

The measurement of glycogenolysis was carried out in glycogen-rich hepatocytes prepared according to Shiroyama et al. (1998). These cells are suitable for determination of agonist-induced glycogenolytic glucose release in glucose-free incubation medium. Significantly higher nitrite levels produced by glucagon were observed $60 \mathrm{~min}$ after the incubation of hepatocytes in culture. The effect of glucagon on NO production is expected to occur at later time than the effect on glucose. This is due to the fact that NO is not directly measured but rather its oxidation product in the medium, i.e. nitrite/nitrate, which needs time to be formed from NO.

Taken together, it seems that glucagon- and $\alpha$-adrenergic-induced glycogenolysis that are mediated via the agonist/adenylyl cyclase/PKA cascade and 
Table 1. The relative effect of incubation (30 and $60 \mathrm{~min}$ ) with glucagon $(1 \mu \mathrm{g} / \mathrm{ml})$, aminoguanidine $(A G, 10 \mathrm{mM})+$ glucagon, $\mathrm{N}^{\omega}$-nitro-L-arginine methyl ester (L-NAME, $10 \mathrm{mM}$ ) + glucagon, dibutyryl cAMP (db-cAMP, $1 \mathrm{mM}$ ) and forskolin (50 $\mu \mathrm{M})$ treatments on nitrite production and glucose release from hepatocytes in culture (mean values \pm S.E.M. of 20-24 cultures).

\section{Treatments}

\begin{tabular}{|c|c|c|c|c|}
\hline & \multicolumn{4}{|c|}{ Percent of control $^{\mathrm{a}} \pm \mathrm{SEM}$} \\
\hline & \multicolumn{2}{|c|}{ Nitrite $(\mu \mathbf{M})$ after } & \multicolumn{2}{|c|}{ Glucose $(\mu \mathrm{M})$ after } \\
\hline & $30 \mathrm{~min}$ & $60 \mathrm{~min}$ & $30 \mathrm{~min}$ & $60 \mathrm{~min}$ \\
\hline Glucagon & $114 \pm 15$ & $133 \pm 11 *$ & $267 \pm 25^{*}$ & $148 \pm 12 *$ \\
\hline $\begin{array}{l}A G+ \\
\text { glucagon }\end{array}$ & $75+5 *$ & $53 \pm 5^{*}$ & $90 \pm 15$ & $117 \pm 10$ \\
\hline $\begin{array}{l}\text { L-NAME + } \\
\text { glucagon }\end{array}$ & $150 \pm 8^{*}$ & $76 \pm 6^{*}$ & $191 \pm 30^{*}$ & $150 \pm 15^{*}$ \\
\hline$d b-c A M P$ & $120 \pm 10 *$ & $160 \pm 8^{*}$ & $140 \pm 10 *$ & $90 \pm 25$ \\
\hline Forskolin & $116+4 *$ & $120+3 *$ & $147 \pm 13 *$ & $75 \pm 8^{*}$ \\
\hline
\end{tabular}

${ }^{*}$ Significantly different from control $(P \leq 0.05)$.

a Percent of the amount of produced nitrite or glucose in treated culture per the amount in appropriate control culture (treated/control x 100).

cAMP signaling pathway or via the activation of phosphorylase kinase by the mobilized calcium that is aided by the inhibition of glycogen synthase (Dempsey et al. 2000), may involve downstream NO production. This is further evidenced by the adenylyl cyclase activator, forskolin, and the stable congener to cAMP, $\mathrm{db}$-cAMP, because both of them produce qualitatively identical effects on glycogenolysis and NO production as glucagon. Moreover, we added SNAP at two concentrations to hepatocyte culture, and we observed dose-dependent increase in basal glycogenolysis. Accordingly, we may suggest that endogenous NO produced downstream of agonist/receptor signal transduction pathway and coupling through an isoform of NOS, plays a role in glycogenolysis. This is further supported by our data demonstrating that aminoguanidine (and to some extent also L-NAME) were able to partially inhibit the glycogenolytic effect of glucagon and epinephrine. Moreover, iNOS mRNA was significantly enhanced by both glucagon (present data) and epinephrine (Hodis et al. 2007). The present data do not rule out the involvement of either NOS isoform in contributing to the glycogenolytic signaling pathway(s) in isolated cultured hepatocytes. Recently, we have found a similar involvement of NO signaling during $\beta$ adrenergic lipolysis in rat white adipocytes (KutinovaCanova et al. 2006) indicating the widespread role of
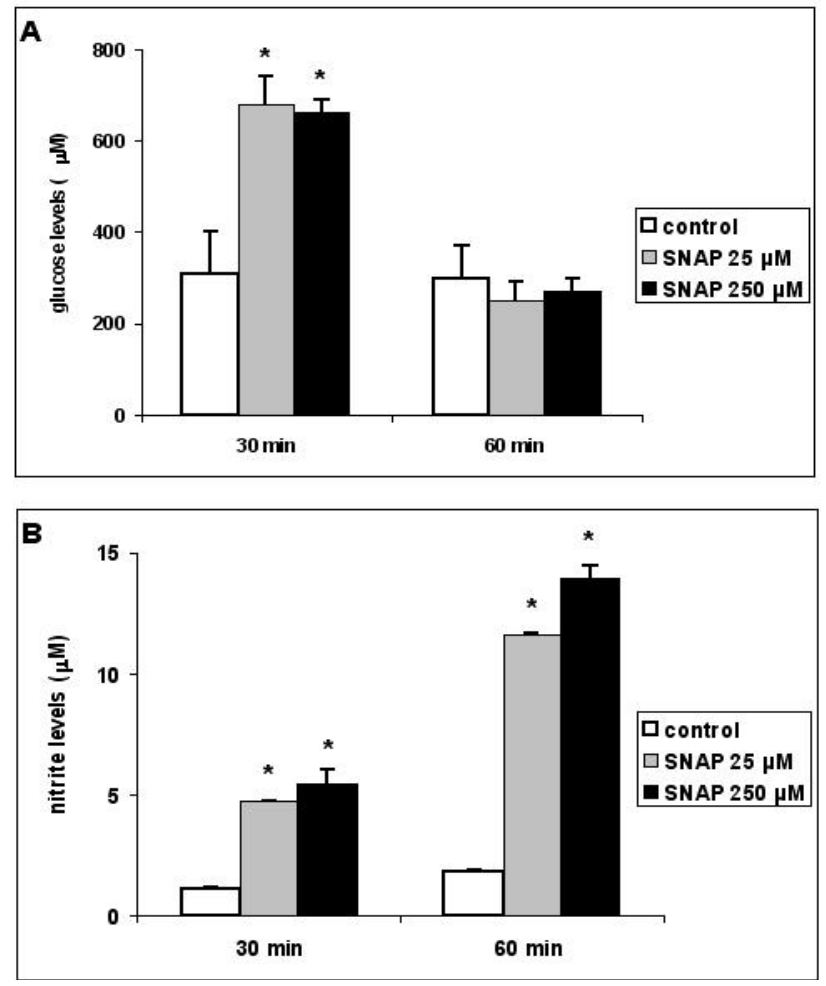

Fig. 3. The effect of S-nitroso-N-acetyl penicillamine (SNAP, 25 and $250 \mu \mathrm{M}$ ) treatment on glucose (A) and nitrite (B) release from glycogen-rich hepatocytes cultured for 30 and $60 \mathrm{~min}$. Values are expressed as means \pm S.E.M. * Significantly different from the respective control group $(P \leq 0.05)$.

$\mathrm{NO}$ in various pathophysiological processes of the liver as well as other well established functions in other organs and tissues.

In summary, our studies may suggest that under the present experimental conditions, endogenous NO is produced downstream of glucagon- receptor or $\alpha$-adrenoceptor signal transduction pathways through an isoform of NO synthases and that it plays a role in glocogenolysis. This is supported by our findings that: 1) glucagon and epinephrine increased $\mathrm{NO}$ and simultaneously stimulated glycogenolysis, 2) prazosin (a selective $\alpha$-adrenergic blocker) but not propranolol (non selective $\beta$-adrenergic blocker) was able to inhibit the glycogenolytic effect of $\alpha$-adrenergic agonists concomitantly with a reduction of the amount of nitrite formed in the medium, 3) both glucagon and epinephrine increased iNOS mRNA, 4) db-cAMP and the adenlyl cyclase activator, forskolin, stimulated both nitrite production and glucose release, 5) NO exogenously delivered through SNAP to hepatocyte culture stimulated glycogenolysis, and 6) inhibitors of NO synthase reduced nitrite production and glycogenolysis in cultured rat hepatocytes. However, more studies are needed to further clarify of NO role in glycogenolysis. 


\section{Conflict of Interest}

There is no conflict of interest.

\section{Acknowledgements}

The authors would like to thank Libuše Šlehobrová and
Alena Hloušková for their skilful technical assistance. This work was supported by the research grants: IGA MZ NR/9373-3/2007, GAČR 305/05/2425, and VZ MSM 0021620807.

\section{References}

BORGS M, BOLLEN M, KEPPENS S, YAP SH, STALMANS W, VANSTAPEL F: Modulation of basal hepatic glycogenolysis by nitric oxide. Hepatology 23: 1564-1571, 1996.

CHANG K, LEE SJ, CHEONG I, BILLIAR TR, CHUNG HT, HAN JA, KWON YG, HA KS, KIM YM: Nitric oxide suppresses inducible nitric oxide synthase expression by inhibiting post-translational modification of $1 \mathrm{\kappa B}$. Exp Mol Med 36: 311-324, 2004.

DECKER K: Biologically-active products of stimulated liver macrophages (Kupffer cells). Eur J Biochem 192: 245261, 1990.

DEMPSEY EC, NEWTON AC, MOCHLY ROSEN D, FIELDS AP, RAYLAND ME, INSEL PA, MESSING RO: Protein kinase $C$ isozymes and the regulation of diverse cell responses. Am J Physiol 279: L429-L438, 2000.

FABBRI E, BUZZI M, BIONDI C, CAPUZZO A: Alpha-adrenoceptor mediated glucose release from perifused catfish hepatocytes. Life Sci 65: 27-35, 1999.

FARGHALI H, KAMENÍKOVÁ L, HYNIE S: Preparation of functionally active immobilized and perfused mammalian cells: an example of hepatocyte bioreactor. Physiol Res 43: 121-125, 1994.

FARGHALI H, CANOVÁ N, GAIER N, LINCOVÁ D, KMONÍČKOVÁ E, STREŠTÍKOVÁ P, MAŠEK K: Inhibition of endotoxemia-induced nitric oxide synthase expression by cyclosporin A enhances hepatocyte injury in rats: amelioration by NO donors. Int Immunopharmacol 2: 117-127, 2002.

FRAEYMAN N, VAN ERMEN A: Influence of aging on the beta- and glucagon-receptor-mediated glycogenolysis in rat hepatocytes. Mech Ageing Dev 70: 115-126, 1993.

HARBRECHT BG, PERPETUA M, FULMER M, ZHANG BC: Glucagon regulates hepatic inducible nitric oxide synthesis in vivo. Shock 22: 157-162, 2004.

HODIS J, KUTINOVÁ-CANOVÁ N, POTMĚŠIL P, KAMENÍKOVÁ L, KMONÍČKOVÁ E, ZÍDEK Z, FARGHALI $\mathrm{H}$ : The role of adrenergic agonists on glycogenolysis in rat hepatocyte culture and possible involving of NO. Physiol Res 56: 419-425, 2007.

HORTON RA, KNOWLES RG, TITHERADGE MA: Endotoxin causes changes in hepatic nitric-oxide synthesis, gluconeogenesis, and flux through phosphoenolpyruvate carboxykinase. Biochem Biophys Res Commun 204: 659-665, 1994a.

HORTON RA, CEPPI ED, KNOWLES RG, TITHERADGE MA: Inhibition of hepatic gluconeogenesis by nitric oxide - a comparison with endotoxic shock. Biochem J 299: 735-739, 1994b.

HUBER M, KEPPLER D: Eicosanoids and the liver. Prog Liver Dis 9: 117-141, 1990.

KALAMIDAS SA, KOTOULAS OB, HANN AC: Studies on glycogen autophagy: effects of phorbol myristate acetate, ionophore A23187, or phentolamine. Microsc Res Tech 57: 507-511, 2002.

KLOVER PJ, MOONEY RA: Hepatocytes: critical for glucose homeostasis. Int J Biochem Cell Biol 36: 753-758, 2004.

KUTINOVÁ-CANOVÁ N, LINCOVÁ D, KMONÍCKOVÁ E, KAMENÍKOVÁ L, FARGHALI H: Nitric oxide production from rat adipocytes is modulated by $\beta_{3}$-adrenergic receptor agonists and is involved in a cyclic AMP-dependent lipolysis in adipocytes. Nitric Oxide-Biol Chem 14: 200-211, 2006.

MANZL C, SCHUBERT M, SCHWARZBAUM PJ, KRUMSCHNABEL G: Effects of chemical anoxia on adrenergic responses of goldfish hepatocytes and the contribution of alpha- and beta-adrenoceptors. $J$ Exp Zool 292: 468476, 2002.

MOREAU R: Are nitric oxide synthases new players in the pathopysiology of fulminant hepatic failure? $J$ Hepatol 37: 678-680, 2002. 
MORIYAMA M, NAKANISHI Y, TSUYAMA S, KANNAN Y, OHTA M, SUGANO T: Change from beta- to alphaadrenergic glycogenolysis induced by corticosteroids in female rat liver. Am J Physiol 273: R153-R160, 1997.

MURIEL P: Regulation of nitric oxide synthesis in the liver. J Appl Toxicol 20: 189-195, 2000.

PROIETTO J, ANDRIKOPOULOS S: Molecular mechanisms of increased glucose production: Identifying potential therapeutic targets. J Investig Med 52: 389-393, 2004.

SHIROYAMA K, MORIWAKI K, YUGE O: The direct effect of dopamine on glucose release from primary cultured rat hepatocytes. In vivo 12: 527-529, 1998.

STADLER J, BARTON D, BEIL-MOELLER H, DIEKMANN S, HIERHOLZER C, ERHARD W, HEIDECKE CD: Hepatocyte nitric-oxide biosynthesis inhibits glucose output and competes with urea synthesis for L-arginine. Am J Physiol 268: G183-G188, 1995.

SUGITA H, KANEKI M, TOKUNAGA E, SUGITA M, KOIKE C, YASUHARA S, TOMPKINS RG, JEEVENDRA M: Inducible nitric oxide synthase plays a role in LPS-induced hyperglycemia and insulin resistance. Am $J$ Physiol 282: E386-E394, 2002.

VAN ERMEN A, FRAEYMAN N: Desensitization of $\alpha_{1}$-receptor, beta-receptor and glucagon-receptor in rat hepatocytes - influence of ageing. Mech Ageing Dev 75: 45-58, 1994.

VARDANEGA-PEICHER M, LOPES G, LIMA FB, CURI R, NAKANO LC, BAZOTTE PB: Time sequence of changes in the responsiveness of glycogen breakdown to adrenergic agonists in perfused liver of rats with insulin-induced hypoglycemia. Braz J Med Biol Res 33: 805-813, 2000.

VOLETI B, AGRAWAL A: Statins and nitric oxide reduce C reactive protein production while inflammatory conditions persist. Mol Immunol 43: 891-896, 2006. 